\title{
A Game Theory-Based Approach for Exploring Water Resource Exploitation Behavior in the Poyang Lake Basin, China
}

\author{
Tiangui Lv ${ }^{1,2}$, Hualin $\mathrm{Xie}^{2}$, Hua Lu ${ }^{2, * \mathbb{D}}$, Xinmin Zhang ${ }^{2}$ and Lei Yang ${ }^{1}$ \\ 1 School of Tourism and Urban Management, Jiangxi University of Finance and Economics, \\ Nanchang 330013, China; lvtiangui@163.com (T.L.); yanglei9712@163.com (L.Y.) \\ 2 Institute of Ecological Civilization, Jiangxi University of Finance and Economics, Nanchang 330013, China; \\ xiehualin@jxufe.edu.cn (H.X.); zhangxm1217@yahoo.com (X.Z.) \\ * Correspondence: luhuanj@126.com; Tel.: +86-791-8397-9115
}

Received: 28 September 2019; Accepted: 29 October 2019; Published: 7 November 2019

\begin{abstract}
Exploring the relationship between competition and cooperation in water resource exploitation by applying a game model is crucial for achieving stable equilibrium in the presence of environmental externalities. To explore this, we used the Poyang Lake Basin, which is divided into three overly exploited sub-regions, as an example. This paper selected the different types of sub-regions of Poyang Lake Basin as the research subjects, and then proposed a game model to study evolutionarily stable equilibrium strategies. The results are as follows: (1) the behavior of the sub-regions of Poyang Lake Basin are affected by one another and cannot achieve equilibrium through independent games, which also need external forces to coordinate the three reaches; (2) the benefits improve gradually from the state of "non-cooperation" to "full cooperation" and reach an ideal equilibrium when all the sub-regions choose the strategy of cooperation; (3) the strategic choice of sub-reaches is difficult to maximize the overall benefits of the basin in the absence of external constraints. To ensure that the sub-regions choose the cooperative strategy, the central government should support the cooperative subsidies of local governments. In addition to improving the equilibrium state of the sub-reaches, this study proposes the following policy implications: constructing a basin plan and promoting fiscal transfer payments, inducing an industrial gradient transfer, and strengthening the payment for the use of water resources.
\end{abstract}

Keywords: competition; cooperation; water resource exploitation; game model; Poyang Lake Basin

\section{Introduction}

In recent years, water resource exploitation has been an important way to achieve regional development in many countries [1,2]. It has been reported that basins represent a special type of region with strong integrity and a high degree of correlation [3]. In essence, the research has demonstrated that water resource exploitation of a basin is interrelated with social-economic development [4]. It has also been suggested that basin development not only involves the functions of water resource carrying capacity, navigation, and landscape ecology, but also is associated with the goal of coordinated planning. In fact, users are especially connected with one another because the common-pool resources that are closely related to the ecosystem can be affected by the level of coordination among the upper, middle, and lower reaches [5]. In the basin area, many case studies have demonstrated that regional conflict is primarily accelerated by water resource exploitation [6]. In particular, the over-exploitation of water resources is likely to cause lakes to shrink, water pollution, ecosystem degradation, etc. [7]. These problems have seriously hindered the coordination of water resource exploitation and need to be urgently tackled. The local government is the main authoritative body behind water resource 
exploitation. Recently, some studies have discussed regional conflicts related to water resource exploitation at the provincial scale. Meanwhile, the current research related to basin development focuses on inter-regional coordination, and very few cases of water resource exploitation have been studied across different regions in a basin. Thus, it is crucially important to analyze the competition and cooperation behavior in water resource exploitation in the basin.

Many studies on the coordination status of water resource exploitation have usually focused on one or more aspects, and their studies also show that exploration is related to the coordination between land resource utilization and environmental protection, especially in watershed management [8-10]. In general, these studies have focused on two aspects. On the one hand, optimal modelling has been employed to analyze the problem of high-quality water resource allocation from the perspectives of game theory, the economic coordination model, and the environmental standards for water management in the basin [9]. In addition, one study has described the management status of different types of basins in Africa [10]. Obviously, a single measurement cannot capture the coordination across departments, and the results show that poor monitoring and low enforcement are the main factors that impede the coordinated development of the basin economy [11]. Furthermore, several studies have focused mainly on inter-basin coordination, while few have focused on economic coordination in small- and medium-sized basins. Furthermore, regarding the division of the main functional areas, coordination mechanisms of regional interests and administrative interests have been proposed to standardize spatial development in different sections of the basin.

Accordingly, an important theoretical branch in the literature focuses on sustainable watershed management based on the multi-objective game theory model [12]. Meanwhile, some researchers have enriched the method of watershed economic coordination during the process of watershed exploitation and management [13]. Additionally, one study has proposed an analysis scheme for the allocation of water resource exploitation in the Tin River Basin that lays a foundation for a win-win cooperation in the trans-boundary river basin from the perspective of trans-boundary basin coordination [14]. However, this scheme is insufficient for describing the gap in the benefits, while considering the different development stages, of the basin. For instance, it does not allow us to obtain direct and precise feature-oriented information about water resource exploitation behavior from different (upper, middle, and lower) regions. Specifically, time series high spatial resolution images are usually unavailable at the megacity level. Moreover, there is a difference in water endowments among the sub-reaches of the basin. Additionally, some studies were performed by considering environmental issues based on game theoretic models from the perspective of water resource exploitation [15].

Unfortunately, some studies have suggested that the main players tend to neglect overall interests and rather pursue individual interests, which causes a continuous expansion of the socio-economic development gap in the basin [16,17]. Furthermore, it is important to improve the coordinated development of water resource exploitation among the upper, middle, and lower reaches of the basin and provide perspectives for solving the regional conflict between the local interests and overall interests of the basin. Under such circumstances, exploring sustainable coordination and its mechanism could have critical implications for basin managers [18]. Hence, there is a need to take water resource exploitation into account and take advantage of the carrying capacity during the process of watershed economic integration.

In summary, most researchers have analyzed the dilemma of water exploitation coordination and then further studied behavior strategy based on the game model. Nevertheless, few studies have discussed the issues of interest to participants in water resource exploitation. In particular, there are insufficient studies that quantitatively analyze the influencing factors related to the choice of water resource exploitation among different types of local governments. Hence, it is necessary to control these influential factors to enable the three sub-reaches to evolve towards a stable equilibrium. Furthermore, this research shows that the game model consists of bounded rationality and asymmetric information theory $[19,20]$. At the same time, water resource exploitation has become an important tool to solve the conflict of interest among participants. Therefore, water resource exploitation can effectively solve the 
conflicts of interest among the participants in different sub-reaches. However, only a few researchers have focused on the interest relationships during water resource exploitation.

Poyang Lake is one of the largest freshwater lakes in China, and plays an important role in the process of economic development and ecological protection in Jiangxi Province. History also shows that the water resource exploitation in the Poyang Lake Basin has promoted regional social development and economic growth in the process of urbanization. Therefore, local governments pursue the construction of more reservoirs to obtain benefits. However, these water resource development activities cause serious water shortages, especially in the middle and lower reaches of Poyang Lake Basin. The motivation of this study is derived from the conflict that involves water resource exploitation among the local governments that surround the Poyang Lake Basin, China [21,22]. These regions have utilized increasing amounts of water resources in the process of rapid economic growth in recent years [23]. To solve the problem of water shortage, some local governments have begun to build dams or reservoirs or have asked the central government for approval to build these projects. Notably, as a special type of region with strong integrity and a high degree of relevance, the basin in the upper, middle, and lower reaches is interrelated. Additionally, one study shows that the industrial development and agricultural production lead to the deterioration of the water quality in Poyang Lake Basin [24]. Therefore, the Poyang Lake Basin is a representative example for improving the coordination degree of water resource exploitation. Thereby, this study explores and discusses the behavior strategies of local governments among different sub-reaches in the basin's development and the optimal strategy. Accordingly, this paper considers Poyang Lake Basin as an example, and we use the dynamic game theory model and propose a theoretical framework to investigate multiple regions to achieve sustainable and coordinated development.

\section{Study Area and Modeling}

\subsection{Study Area}

Poyang Lake Basin is located in the middle and lower reaches of the Yangtze River Basin, China (Figure 1). In particular, Poyang Lake Basin spans six provinces, namely, Jiangxi, Anhui, Zhejiang, Fujian, Guangdong, and Hunan Province. The total areas of the Poyang Lake Basin account for approximately $97 \%$ of Jiangxi Province, and the scope of the administrative division is consistent with the boundary of the river basin [25]. In fact, according to geographical proximity, we divided the districts across Poyang Lake Basin into three regions, including the upper reach (UR), the middle reach (MR), and the lower reach (LR) (Figure 1) [26]. First, the LR includes five municipalities (i.e., Nanchang, Jiujiang, Jindezhen, Xinyu, and Fuzhou). In addition, the region has the highest level of industrial development, advanced industrial technology and foreign industrial enterprises in the Poyang Lake Basin. Moreover, the industrial gross domestic product (GDP) in this region accounted for more than $60 \%$ of entire basin's GDP in 2015 [27]. Second, the MR includes two municipalities (i.e., Shangrao and Ji'an). This region is the main base of the agricultural and industrialized areas of Poyang Lake Basin and is also famous for its high consumption of water resources and large discharge of water pollutants. Finally, the UR includes one municipality (i.e., Ganzhou). In addition, the territory of this region is larger than the territory of the other two regions (namely, the LR and MR), but the industrial sector of this region lags behind the industry of the other two regions.

Recently, Poyang Lake has suffered from a severe water shortage due to the lack of rainfall and the pollution from the UR, MR, and LR in addition to the interactive decision to construct dams or reservoirs among the regions [28]. This also shows that the government of the sub-reaches have applied to the central government for the construction of dams or reservoirs to solve the water shortage problem [2]. At the same time, the high cost of building dams and reservoirs means that if there is no restriction from the central government, the upper and middle reaches may obtain the power to use natural resources jointly and exclusively, which has a negative impact on other regions. Moreover, the planning of the Poyang Lake Eco-Economic Zone (PLEEZ) has become a part of the national 
development strategy, and the increasing demand for the construction of ecological barrier areas and the coordination of economic development within the basin has become the inevitable choice for the economic integration of Poyang Lake Basin.

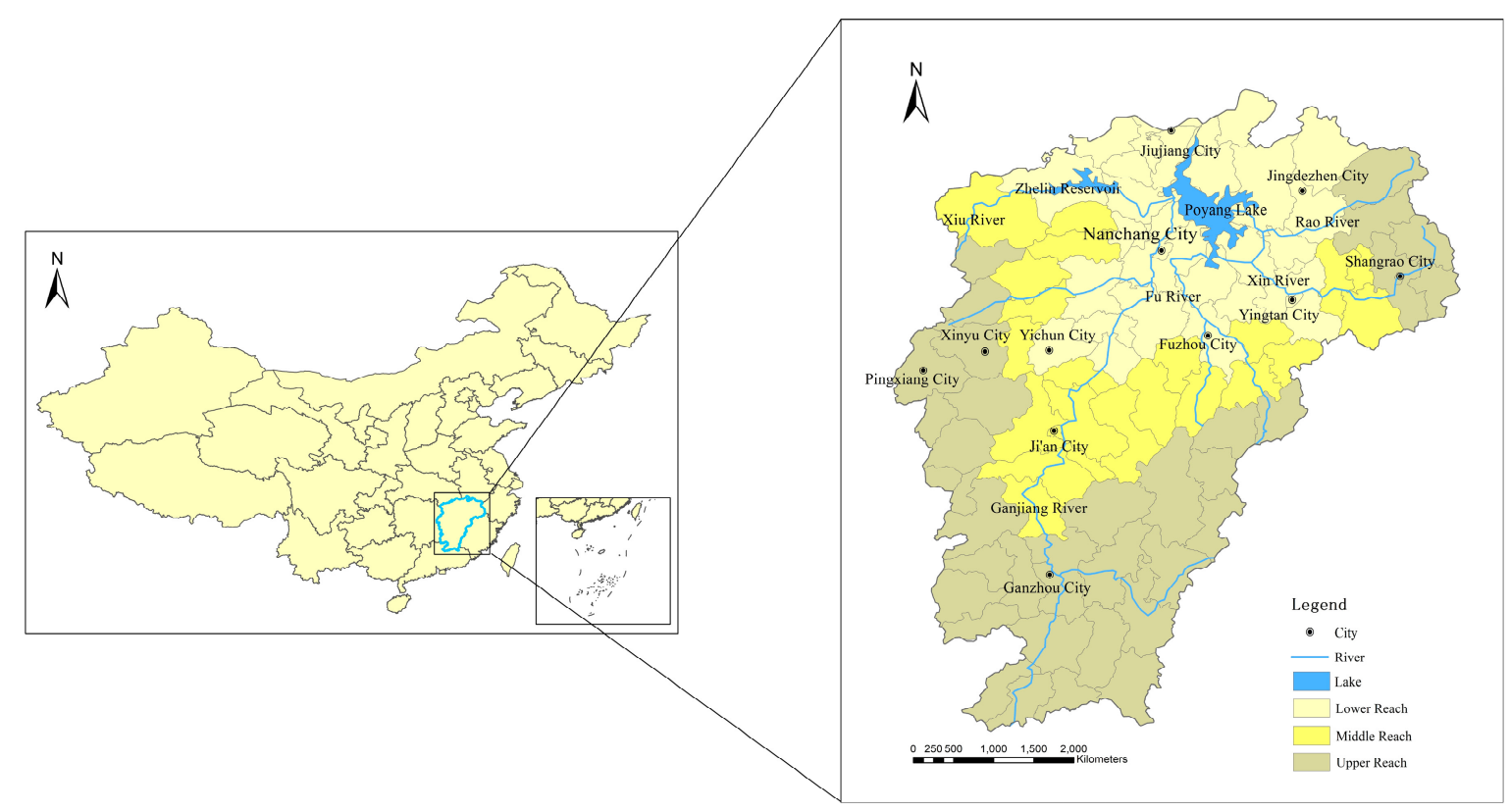

Figure 1. Location of the Poyang Lake Basin, China.

\subsection{Overall Concept of the Game Model Hypothesis}

It is well known that game theory is associated with competition and cooperation among decision makers, and the interests of the subject not only depend on the choices of their behavior but also refer to the behavior choices of other subjects. These aspects provide a tool for the coordination of interest conflicts in the basin [29]. In addition, if the decision makers in the middle or lower reaches of the basin focus on their own benefits during the process of water resource exploitation, the choice of strategies could depend more on their own observations and judgement. Generally, the coordination of water resource exploitation lies in the cooperation system among the upper, middle, and lower reaches of the basin. It is understood that the sub-reaches' local governments should provide public goods (i.e., clean water, etc.) to one another [30]. Furthermore, according to the game theory analysis criteria, the rules of the game are described as follows [30,31].

Hypothesis 1. The local governments of the upper, middle, and lower reaches are assumed to engage in rational behavior.

Hypothesis 2. The game strategy is divided into the two categories of "cooperation" and "non-cooperation". Choosing the strategy of "cooperation" does not require the provision of an acceptable and undifferentiated service S for water resources, while the strategy of "non-cooperation" allows and shares the same service for a non-provider. Thus, the use of "free-rider" behavior is allowed during the process of water resource exploitation in the basin.

Hypothesis 3. Before the depletion of the ecosystem service functions in the basin, the local governments of the lower reach will enjoy the environmental service functions and will not reduce the utilization level or restrict the utilization of other reaches. 
Hypothesis 4. The sub-reaches' local governments can understand their water endowments and market demands, which shows that the action process has a sequential rule. Therefore, the game model is used to capture the behavior of random disturbances to the variables under different scenarios.

\subsection{Key Formulas and Parameter Descriptions of Model Construction}

Based on the above assumptions and to simplify the process, we assumed that the initial ecological value of the water resources at the junction of the upper-middle reach, and middle-lower reach are set to 1 [32-34]. Therefore, the remainder of the key formulas and parameter descriptions are organized as follows.

First, the initial ecological value of the water resources in the border area is equal (e.g., clean water, etc.), but the initial interest without the border area is $R$, specifically, $0<S \leq 2 / 3$ and $S / 2<R \leq 1 / 3$. In addition, the income of the benefit is expressed as $B$, where $B_{i, k, j}$ represents the revenue of choosing strategy $\mathrm{k}$ under the state of $\mathrm{j}$ in the ith area.

Second, the local governments were divided according to the geographical units of Poyang Lake Basin, that is, $i=\{$ upper, middle, lower $\}=\{1,2,3\}$. Furthermore, two game strategies can be chosen by the local governments, where $\mathrm{k}=$ (cooperation, non-cooperation $)=(0,1)$. Additionally, the local governments can have four external game states, that is, $j=\{$ (non-cooperation, non-cooperation), (cooperation, non-cooperation), (non-cooperation, cooperation), (cooperation, cooperation) $\}=\{1,2$, $3,4\}$. The formula of the game model is expressed as follows:

$$
\mathrm{Bi}, \mathrm{k}, \mathrm{j}=\mathrm{Bi}, 0,1+\mathrm{W} \cdot \mathrm{S} \text {. }
$$

$\mathrm{B}_{\mathrm{i}, 0,1}$ is the ecological value of the water resource exploitation under the non-cooperative strategy in the ith area, while $W$ represents the income weight of the ith area under the state of $j$. When $j$ assumes under the game state of $1, \mathrm{~W}$ represents 0 , which indicates that two reaches (e.g., the UR and the MR) of the basin choose the strategy of "non-cooperation", while both of them do not have to provide the water resource services to one another. Furthermore, when $j$ assumes under the states of 2 and 3, respectively, $\mathrm{W}$ is 1 . This means that one reach (e.g., the UR or the MR) chooses the strategy of "cooperation" and another reach chooses the strategy of "non-cooperation", and cooperative reach can only generate $S$ units of water resource service. When $j$ assumes under the game state of $4, W$ is 2 . This means that both sides of the board can choose "cooperation" to provide water resource services to one another and generate $2 \mathrm{~S}$ units of water resource service.

\section{Game Results}

\subsection{Game Results and the Stable Equilibrium of the Game}

Given the settings of the game hypothesis, we conducted a descriptive statistical analysis of the characteristics of the tripartite game matrix among the upper, middle, and lower reaches of Poyang Lake Basin (Table 1).

According to Table 1, the results shows that there are two optimal solutions to coordinate the game of water resource exploitation in the sub-reaches of Poyang Lake Basin.

(1) In this situation, when one of the participants chooses the strategy of cooperation, it means that other members need to provide acceptable and undifferentiated water resource services to one another. In addition, the value of the water resources service is increased to $2 \mathrm{~S}$ due to the mutual provision of water resources when three parties (i.e., the upper reach, the middle reach, and the lower reach) choose the strategy of cooperation. It can be concluded that the maximum benefit of the value of the water resources service could reach to $2+6 \mathrm{~S}$, as indicated in Table 1 .

(2) Additionally, Table 1 shows that all participants choose the strategy of non-cooperation, which indicates that the ecosystem service functions of water resources can maintain only the initial interest, while the minimum revenue is 2 . Additionally, the external characteristics of the 
ecosystem service functions of water resources and the possibility of "free-riders", reflecting that any party could withdraw from the strategy of cooperation for all of them and still maintain their income while reducing the income of the other two reaches of the basin. Moreover, the overall benefits would be reduced to $2 \mathrm{~S}$ if any reach of the basin withdraws from the cooperative state.

Therefore, the individual response of any rational participant in the upper, middle, and lower reaches of the Poyang Lake Basin while choosing the "non-cooperative" strategy is to maximize their own interests, while ultimately minimizing the overall benefit and individual interests. Therefore, a "dilemma" exists due to the deviation between the game rationality and the social expectation of the regional government in the basin. In addition, it suggested that the development of this problem is associated with the social-economic development in the sub-reaches of the basin. However, the local government in the lower reach believes that the governments of the middle and upper reaches are reasonable without paying the corresponding costs, while the middle reach of the local government hopes to control downstream industries and enjoys the water resource services provided by the upper reach. Additionally, the local government of the upper reach believes that its development rights should not be sacrificed during the process of urbanization. Ultimately, the choices of interests in the sub-reaches of the basin contradict the expectation based on the overall interests of society due to the different interests of the people in Poyang Lake Basin.

Table 1. Game matrix of competition and cooperation in the upper, middle, and lower reaches.

\begin{tabular}{cccccc}
\hline \multirow{2}{*}{ Type } & \multicolumn{3}{c}{ Lower } \\
\cline { 3 - 5 } & & \multicolumn{2}{c}{ Cooperation } & \multicolumn{2}{c}{ Non-Cooperation } \\
\cline { 2 - 5 } & & \multicolumn{2}{c}{ Middle } & \multicolumn{2}{c}{ Middle } \\
\cline { 3 - 6 } & \multirow{2}{*}{ Cooperation } & Non-Cooperation & Cooperation & Non-Cooperation \\
\hline \multirow{3}{*}{ Upper } & \multirow{2}{*}{ Cooperation } & $(1+\mathrm{R}) / 2+2 S, 1-\mathrm{R}$ & $(1+\mathrm{R}) / 2+\mathrm{S}, 1-\mathrm{R}$ & $(1+\mathrm{R}) / 2+\mathrm{S}, 1-\mathrm{R}$ & $(1+\mathrm{R}) / 2,1-\mathrm{R}+\mathrm{S}$, \\
& & $+2 \mathrm{~S},(1+\mathrm{R}) / 2+2 \mathrm{~S}$ & $+2 \mathrm{~S},(1+\mathrm{R}) / 2+\mathrm{S}$ & $+\mathrm{S},(1+\mathrm{R}) / 2+2 \mathrm{~S}$ & $(1+\mathrm{R}) / 2+\mathrm{S}$ \\
& \multirow{2}{*}{ Non-Cooperation } & $(1+\mathrm{R}) / 2+2 \mathrm{~S}, 1-$ & $(1+\mathrm{R}) / 2+\mathrm{S}, 1-\mathrm{R}$ & $(1+\mathrm{R}) / 2+\mathrm{S}, 1-\mathrm{R}$, & $(1+\mathrm{R}) / 2,1-\mathrm{R}$, \\
& $\mathrm{R}+\mathrm{S},(1+\mathrm{R}) / 2+\mathrm{S}$ & $+\mathrm{S},(1+\mathrm{R}) / 2$ & $(1+\mathrm{R}) / 2+\mathrm{S}$ & $(1+\mathrm{R}) / 2$ \\
\hline
\end{tabular}

Note: $\mathrm{S}$ indicates that the partners need to provide acceptable and non-differentiated water resources service. $\mathrm{R}$ represents the initial social and economic benefits of non-border areas.

\subsection{Selection of the Cooperative Organizational Structure}

From the above analysis, the strategy of the non-cooperative game is suggested to differ from the stable equilibrium development of the basin. In addition, we should abandon the single game rationality and choose the cooperation structure. Additionally, according to the number of partners from 0 to 3, the structure of cooperative organizations can be divided into non-cooperative entities (e.g., single cooperation, dual cooperation, and whole cooperation). Therefore, the cooperative organization needs pay more attention to the overall benefit if the goal is to achieve a stable equilibrium strategy. Furthermore, the results demonstrate that we can deduce the quantitative relationship and change the rules of the organizational structure evolution (Table 1 and Figure 2).

(1) As each member of the hierarchy is added, the overall benefit will increase by $2 S$ until the "whole cooperation" state is achieved. Furthermore, each member's overall income could reach up to $6 \mathrm{~S}$ more than their income in the "cooperative" state, and the benefit could be at the level of maximization (Figure 3). Thus, this strategy represents the optimal method to improve the efficiency of the upper and middle reaches of Poyang Lake Basin. Therefore, the state of "whole cooperation" can achieve the Pareto-optimal overall interests and individual interests from the perspective of economics.

(2) Regarding individual benefits, the overall benefit could increase by $2 S$ when each level of cooperation is increased. In essence, the external characteristics of water resources with ecological service functions in the middle and lower reaches of the basin easily create "free-riders" in 
association with the interaction between the game strategy selection and as the income level increases. This finding suggests that the benefit level of each participant is not only influenced by self-selection but also depends on the level of benefits and the other participants.

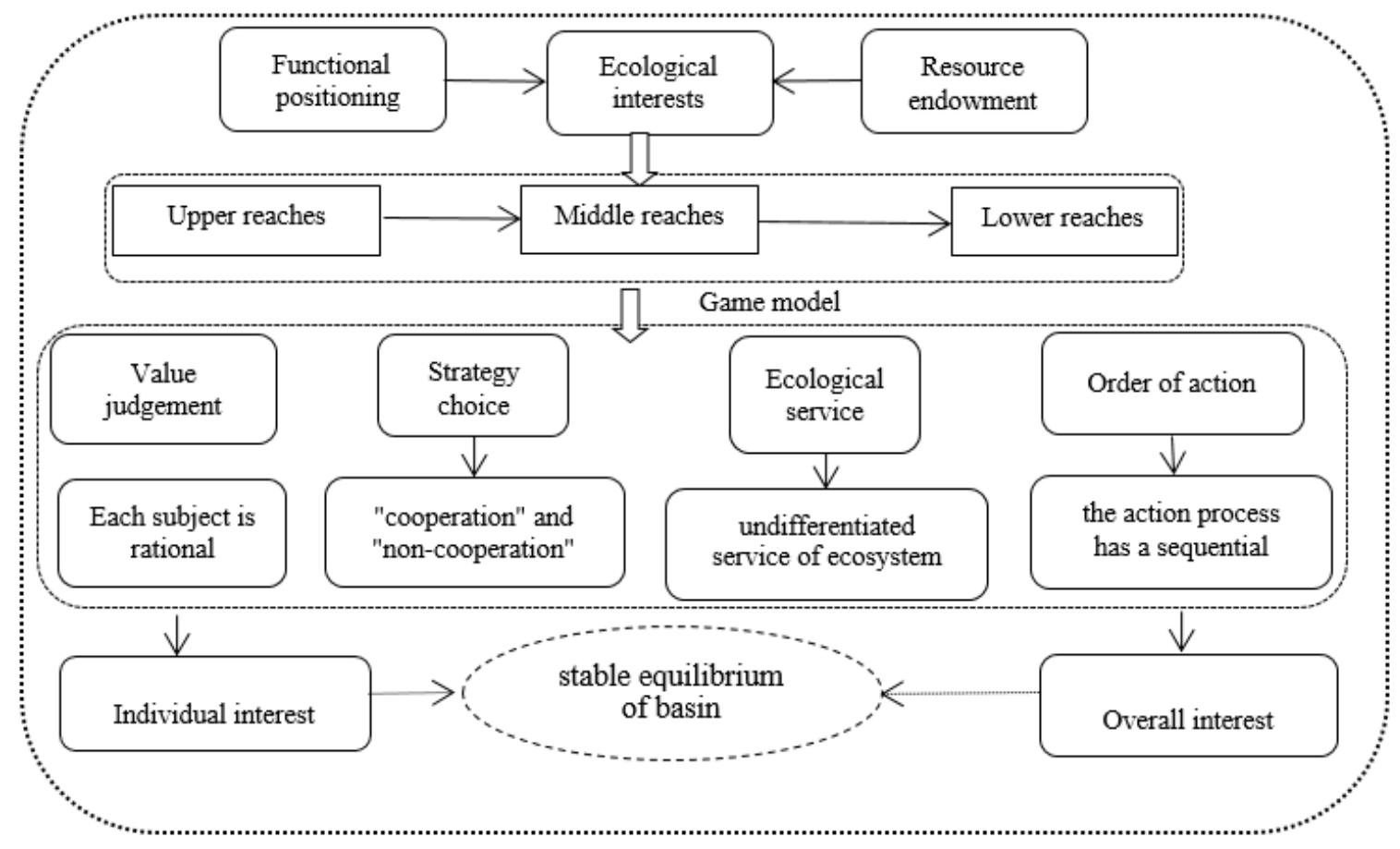

Figure 2. Conceptual framework of the game model.

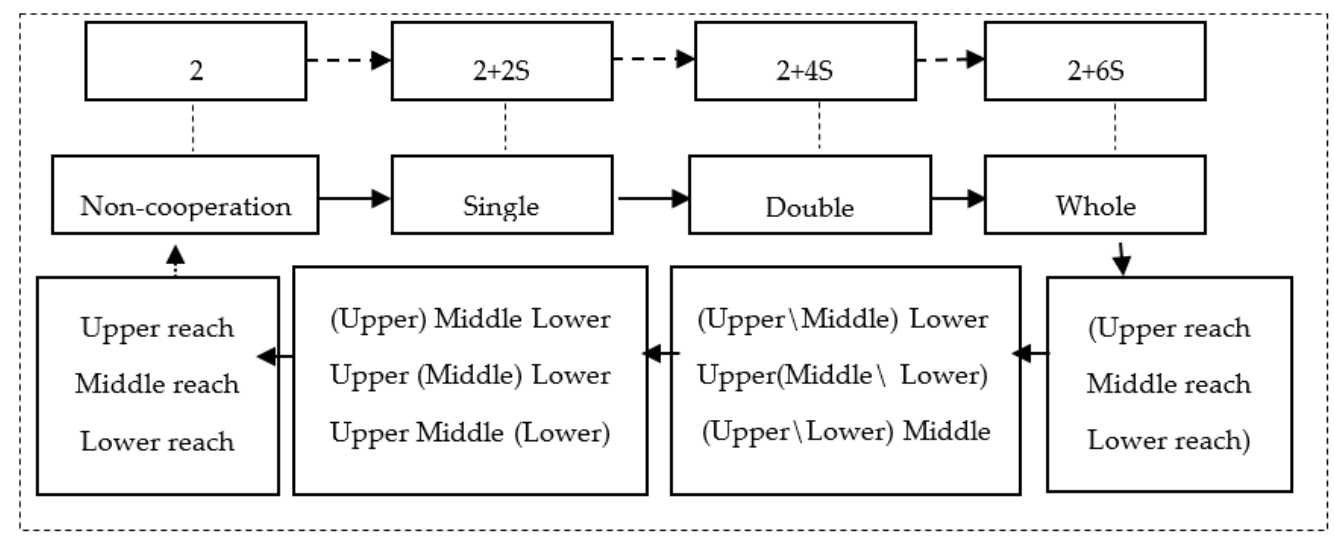

Figure 3. Process of competition and cooperation in the upper, middle, and lower reaches of Poyang Lake Basin.

Meanwhile, it can be observed that a cross-interaction mechanism exists between the strategic choice of cooperative organization and individual game revenue. In addition, the strategy selection of the organization participants is not synchronized with the goal orientation and realization path of the participants, which renders it difficult to form an effective internal cohesive force. The external dynamics must be used to ensure the steady evolution of the organizational structure to the Pareto state to maintain a balanced economic development target in the Poyang Lake Basin.

Based on the above results, we find that any cooperation strategy is a stable equilibrium strategy, while the local government in the sub-reach of the basin has no subsidy. This means that if the local government of a sub-reach of Poyang Lake Basin does not receive the subsides, this reach would not choose the cooperation strategy because of an imbalance in natural resources endowment. That is, 
under the current conditions, there is no guarantee that all partners will choose the cooperation strategy. Thus, we should introduce a third party through the establishment of a restraint mechanism to restrain the reaches and ensure the smooth implementation of a cooperation strategy.

\subsection{Constraint Analysis of the Sub-Regions towards the Stable Equilibrium Strategy}

\subsubsection{Restriction of the Interest Demand Difference}

As a complex eco-economic system, there are differences in the functional orientation, economic benefits, ecological benefits, and resource endowments, which render it difficult to form a consensus regarding the coordination of water resource exploitation among the upper, middle, and lower reaches of Poyang Lake Basin (Table 2). It has been demonstrated that the upper reach has an advantage of geographical location, as it covers the ecological protection zones and water resource conservation zones [35]. Additionally, the local government hopes to reduce soil erosion and obtain equal development rights through the coordinated development of the regional economy. Meanwhile, it is known that the middle reach represents the ecological system buffer zone where industry is undertaken. Finally, the rapid development of industrialization and urbanization in the lower reach of the basin has generated a huge demand of water resource services (e.g., good water quality, etc.) [36]. Therefore, the advantages in the aspects of talent, technology and equipment have become the driving force of industrial development to subsequently expand the scope of their economic emanation.

Table 2. The interest demand in the sub-reaches of Poyang Lake Basin.

\begin{tabular}{clll}
\hline Sub-Region & Functional Positioning & Ecological Interests & Resource Endowment \\
\hline Upper reach & $\begin{array}{l}\text { Water resources and } \\
\text { ecosystem protection } \\
\text { area }\end{array}$ & Ecosystem protection area & Mineral, land, and labor \\
Middle reach & $\begin{array}{l}\text { Ecological protection } \\
\text { buffer and industrial } \\
\text { undertaking area }\end{array}$ & $\begin{array}{l}\text { Protecting the ecological } \\
\text { environment in transition to } \\
\text { achieve social and economic } \\
\text { development }\end{array}$ & Land and labor force \\
\hline Lower reach & $\begin{array}{l}\text { Industrialization and } \\
\text { urbanization }\end{array}$ & $\begin{array}{l}\text { Large demand for water and } \\
\text { soil resources and an obvious } \\
\text { imbalance in the ecological } \\
\text { environment due to a lack of } \\
\text { attention }\end{array}$ & $\begin{array}{l}\text { Capital, talent, } \\
\text { technology, and market }\end{array}$ \\
\hline
\end{tabular}

\subsubsection{Different Levels of Cooperation in the Basin}

Table 2 demonstrates that the upper, middle, and lower reaches are at different development stages in Poyang Lake Basin. For example, the lower reach of the basin is in a rapid development stage, while the middle and upper reaches are still in an exploration stage. Especially, the planning of the Poyang Lake Eco-economic Zone has risen to the level of the national development strategy, which means that the lower reach has obvious advantages in land, finance, and industry [8]. Regrettably, the middle and upper reaches cannot share in this preferential policy. Therefore, the middle and lower reaches of the basin are prone to diverge or even create a conflict of interest in terms of the organization level and cooperation model based on policy differences.

\subsubsection{Internal Constraints of Natural Resources Endowment}

The five major rivers in Poyang Lake Basin have unique geographical elements, and the upper and middle reaches are fragile and sensitive zones of the ecosystem $[9,10]$. This indicates that the water resource exploitation has to face the risks of soil erosion and water pollution because of the different stages of industrialization and urbanization. For instance, the Yuan River (i.e., a branch of the Ganjiang River) Basin mainly faces pesticide pollution, while the Rao River Basin is mainly subjected to the 
pollution from copper mining; additionally, the basins of the Five Rivers still face the impact of various types of industrial and ecological waste-water [1]. Therefore, the rivers (i.e., the Ganjiang River, Rao River, etc.) in Poyang Lake Basin have confronted the risk of the comprehensive exploitation of water resources. As mentioned above, these factors have reduced the enthusiasm and initiative of the upper and middle reaches to coordinate economic development in different stages.

\section{Policy Implications and Discussion}

As mentioned above, we can conclude that the results of the upper, middle, and lower reaches of the game in Poyang Lake Basin may not guarantee the successful cooperation of the water resource exploitation because of the absence of external constraints. Consequently, the basin planning of Poyang Lake and the fiscal transfer payment mechanism to regulate the behavior of the sub-regions have been introduced in this paper. To reduce conflicts of interest and improve the stability of the cooperation state, there is also a need for a corresponding incentive mechanism [37]. As shown in Table 1, when there are the more participants, more benefits $\mathrm{S}$ will be gained from economic cooperation in Poyang Lake Basin. However, the incentive motives for choosing the strategy of cooperation among the reaches in the basin are small. Therefore, we should make good use of the external power of planning policy, fiscal policy, industrial policy, and market policy to reach the state of the stable equilibrium (Figure 4).

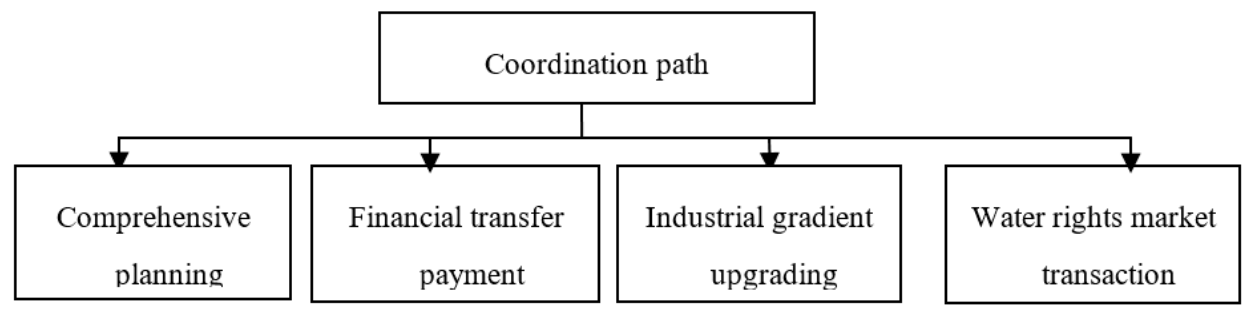

Figure 4. Framework of economic development coordination in Poyang Lake Basin.

\subsection{Policy Implications}

\subsubsection{Constructing Basin Planning to Strengthen the Comprehensive Development}

It demonstrates that an effective method is employed to address the difference in water endowments among the sub-reaches of Poyang Lake Basin to establish comprehensive planning to lead the game matrix towards cooperation [38]. First, it is necessary to formulate comprehensive planning for the development of Poyang Lake Basin by considering the sub-reaches of the planning unit and combining the characteristics of the water endowments of the basin. Then, the industrial structure in the sub-reaches is rationally arranged. Especially, it is necessary to restrain the repeated industrial investment and disorderly competition to reach the goal of orderly water resource exploitation. Second, it is essential to strengthen the comprehensive watershed system by coordinating management and to establish a coordinating mechanism for the basin departments. Meanwhile, it is necessary to clarify the cross functions of different management departments in the sub-reaches of the Poyang Lake Basin. Particularly, an information-sharing mechanism is established to coordinate the basin management and to provide the best spatial organization for the comprehensive management of the basin economy.

\subsubsection{Promoting Fiscal Transfer Payments and Guiding Cooperation to a Stable Equilibrium}

It shows that the benefits of ecological protection in the middle and upper reaches are shared by the lower reaches because of the externality of water resources. All of these lead to the non-synchronous state of cooperation strategies and income, which need the external forces for guidance [39]. Second, it is necessary to establish transfer payments to compensate for the increased expenditure and missed development rights in the middle and upper reaches through financial transfer at the provincial or national level [40]. In addition, the overall interests of the people will be externalized, the overall 
interests of the basin will be guided from 2 to $2+6 \mathrm{~S}$ in the form of funds, and the uncertainty of the cross interaction of the income will be reduced in the form of financial transfers (Figure 5). Therefore, it is necessary to establish a common development fund of the basin and to standardize a financial transfer payment system by calculating the level of financial income in the lower reaches of Poyang Lake Basin. All of this means that if the expenditure is greater than the income, the form of basin finance will be transferred in the form of a transfer payment.

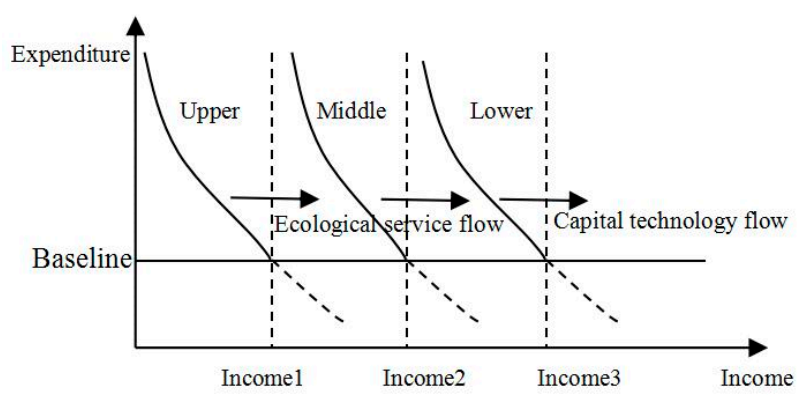

Figure 5. The relationship between fiscal transfer payments and expenditures in Poyang Lake Basin.

4.1.3. Inducing an Industrial Gradient Transfer and Promoting Equilibrium Development

An industrial gradient transfer can form a reasonable division of labor and complementary advantages between the upper and lower reaches, which will promote the overall development of Poyang Lake Basin (Figure 6). Therefore, an industrial gradient transfer should concentrate on the development of the tertiary industry and the diffusion of capital and mature industries into the upper or middle reaches of the basin. Second, it shows that the cities in the middle reaches of Ji'an, Yingtan, and Xinyu should actively accept the lower reach of the industrial transfer, cultivate high-technology industries, accelerate infrastructure construction, and improve the investment environment. Thus, according to the concept of gradient transfer development, the economic predicament of "each independent" in the basin will have been discarded for a long time and will have finally and gradually formed a mutually beneficial and win-win industrial division pattern in the sub-reaches of Poyang Lake Basin.

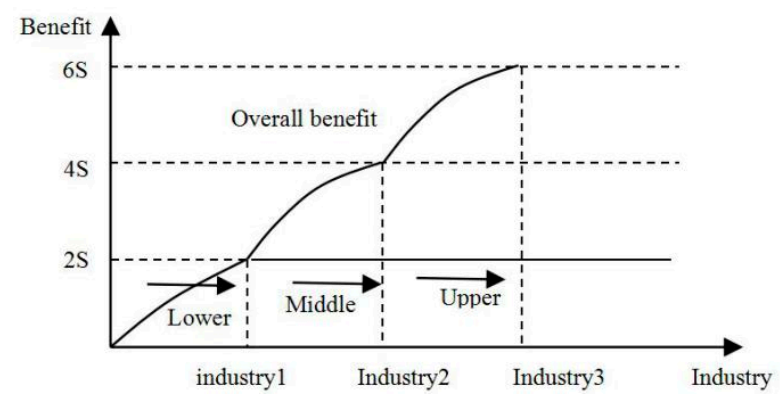

Figure 6. The relationship between the benefit and transfer of industries in Poyang Lake Basin.

4.1.4. Strengthening the Paid Use of Water Resources and Realizing the Marketization of Water Rights Transactions

The water rights trading in the sub-reaches of the basin is beneficial not only for water resource allocation and eco-environmental construction but also for the economic value of the water resource service function. The establishment of the horizontal ecological compensation system among the reaches will be beneficial for the shortage of funds that address the water source protection in the middle and upper reaches and the growth of the ecological system of the basin [41]. Thus, it is necessary to render the water rights of the middle reaches of the basin dominant in the form of industrial transformation and upgrading, public financial payments, and technical personnel assistance, which will be used to pay for ecological water services [42]. Additionally, a mechanism for water rights 
should be introduced in the trading market including that combines bidding, auctions for the right to use, expert evaluations, and tracking management, then, the ecological environmental benefits of water rights transactions are integrated into the unified assessment system.

\subsection{Discussion}

(1) Water resource exploitation has various characteristics, and it quickly raises various conflicts in the upper, middle, and lower reaches of a basin [43-45]. A previous study has observed an increasing tendency of water resource exploitation behavior in the watershed scale [46]. This study presents that Poyang Lake Basin, which is adjacent to some basins, the strategic choice of sub-reaches is difficult to maximize the overall benefits of the basin in the absence of external constraints $[47,48]$. However, we did not observe a significant stable equilibrium effect of these reaches compared with the previous studies, indicating that the central government of the basin can bear the higher cost of water resources protection, while the middle and lower reaches do not maintain a stable equilibrium in early development [49-51]. It is significant to systematically ascertain the conflict of water resource exploitation and its stable equilibrium strategy. However, the previous research has not paid sufficient attention to this theme. Thus, there is no doubt that the strategy of competition or cooperation concerning water resource exploitation can result in stable equilibrium development in the presence of externalization [52].

(2) This paper developed a theoretical framework of a game model to assess the value of cooperation in a basin divided into three overly exploited sub-reaches. Policies should be designed to address the characteristics of non-cooperation, which are caused by individual rationality [53]. The hidden reasons that underlie the phenomena should be further addressed to better coordinate the relationships among the sub-reaches of the basin.

(3) This study takes Poyang Lake Basin as an example, and then analyzes the possible game states in the sub-reaches of the basin from the perspective of game theory. The premise of this hypothesis is a great supplement to the study of the stable equilibrium development of the water resource exploitation in Poyang Lake Basin. However, this study still has some limitations as follows. First, the results regarding the basin cannot be quantified, and there is insufficient research regarding the game state outside the strategy of cooperation or non-cooperation due to the availability of the research data. Simultaneously, this study shows that the enterprises, residents and community are involved as "rational subjects", which is a future research direction concerning the stable equilibrium among the reaches in Poyang Lake basin.

\section{Conclusions}

Under the condition of bounded rationality, we put water resource exploitation into a game model, and then, the stable equilibrium strategy was employed to analyze the Poyang Lake Basin. The main conclusions are described as follows.

(1) Despite the stable equilibrium strategy of the game, the sub-reaches choose the strategy of non-cooperation owing in the main body of the basin because the rational response is to maximize their own interests. At the same time, the overall income and individual income are at the lowest level, which results in a dilemma concerning the development of social expectations.

(2) The stability of the cooperation among the sub-reaches of the basin not only depends on the endogenous power of the economic development of the basin but also needs the support of the external power. Meanwhile, the strategy of non-cooperation is expressed by the constraints of the interest demand difference, the level of cooperation, and the internal constraint of resource endowment. Thus, to ensure that the sub-regions choose the strategy of cooperation, the central government needs to put forward relevant measures to restrict and regulate the behavior of water resource exploitation among the upper, middle, and lower reaches, including comprehensive 
planning, financial transfer payments, industrial transformation, and upgrading and payment for the use of water resources.

(3) The coordination route of the sub-reaches of the Poyang Lake Basin based on the game model can resolve not only the internal conflicts of the basin but also uneven development opportunities, such as resource endowment and location status. At the same time, this study provides a theoretical perspective for the stable equilibrium development of water resource exploitation in Poyang Lake Basin. In addition, the sub-reaches' behavior of non-cooperation is the rational response to maximize their own interests, while the overall rational response is in opposition. Thus, both the overall income and individual income are at the lowest level, which results in the dilemma of deviating from social expectations.

Author Contributions: This research was designed and written by T.L., H.X. and X.Z. The model and results were analyzed by T.L., H.X., H.L., X.Z. and L.Y. All the authors contributed to the final version of the manuscript.

Funding: Funding support for this research includes the National Natural Science Foundation of China (No. 71864016 \& No. 71803071), the Humanity and Social Science Youth Foundation of the Ministry of Education of China (No. 17YJC630100), the Postdoctoral Science Foundation of China (No. 2017M622098), the Postdoctoral Science Foundation of Jiangxi Province (No. 2017KY55), the Postdoctoral Science Daily Foundation of Jiangxi Province (No. 2017RC036), the Natural Science Foundation of Jiangxi Province (No. 20171BAA218017), the Humanities and Social Sciences Fund Project of Jiangxi Province (No. GL18242), the "13th Five-Year" planning project of the Jiangxi Academy of Social Science (No. 16GL31) and the Technology Foundation of the Jiangxi Education Department (No. GJJ160460).

Acknowledgments: We would like to thank the two reviewers for providing constructive comments and valuable suggestions that greatly helped to improve the original manuscript.

Conflicts of Interest: The authors have no conflicts of interest to declare.

\section{References}

1. Chen, M.; Wei, X.; Huang, H.; Lv, T. Poyang Lake basin: A successful, large-scale integrated basin management model for developing countries. Water Sci. Technol. 2011, 9, 1899-1905. [CrossRef] [PubMed]

2. Zhang, N.; Wu, T.; Wang, B.; Ren, J. Sustainable water resource and endogenous economic growth. Technol. Forecast. Soc. Chang. 2016, 112, 237-244. [CrossRef]

3. Teasley, R.L.; McKinney, D.C. Calculating the benefits of trans boundary river basin cooperation: Syr Darya Basin. J. Water Resour. Plan. Manag. 2011, 6, 481-490. [CrossRef]

4. Song, X.; Ravesteijn, W.; Frostell, B.; Wennersten, R. Managing water resources for sustainable development: The case of integrated river basin management in China. Water Sci. Technol. 2010, 2, 499-507. [CrossRef] [PubMed]

5. Milad, M.; Azadeh, A.; Hamid, R. Social resolution of conflicts over water resources allocation in a river basin using cooperative game theory approaches: A case study. Int. J. River Basin Manag. 2016, 14, $33-45$.

6. Luo, Z.; Zuo, Q. Evaluating the coordinated development of social economy, water, and ecology in a heavily disturbed basin based on the distributed hydrology model and the harmony theory. J. Hydrol. 2019, 574, 226-241. [CrossRef]

7. Wu, T.; Zhang, N.; Gui, L.; Wu, W. Sustainable endogenous growth model of multiple regions: Reconciling OR and economic perspective. Eur. J. Oper. Res. 2017, 269, 218-226. [CrossRef]

8. Xu, H.; Liu, J.; Qin, D.Y. Research on water resource exploitation and utilization potential of the Yellow River Basin. Procedia Eng. 2012, 28, 709-714.

9. Moradi, S.; Limaei, S.M. Multi-objective game theory model and fuzzy programming approach for sustainable watershed management. Land Use Policy 2018, 71, 363-371. [CrossRef]

10. Muhandiki, V.; Ballatore, T. Effective lake basin management institutions: Lessons from African lakes. Water Sci. Technol. 2008, 4, 461-483. [CrossRef]

11. Liu, W.; Jiao, F.; Ren, L.; Xu, X.; Wang, J.; Wang, X. Coupling coordination relationship between urbanization and atmospheric environment security in Jinan City. J. Clean Prod. 2018, 10,1-11. [CrossRef]

12. Zuo, Q.T.; Zhao, H.; Mao, C.; Ma, J.; Cui, G. Quantitative analysis of human water relationships and harmony-based regulation in the Tarim River basin. J. Hydrol. Eng. 2015, 20, 1-11. [CrossRef] 
13. Kim, Y.H. International policy coordination mechanism with respect to the moral hazards of financial intermediaries. Econ. Model. 2011, 4, 1914-1922. [CrossRef]

14. Mahjouri, N.; Ardestan, M. A game theoretic approach for inter-basin water resources allocation considering the water quality issues. Environ. Monit. Assess. 2011, 167, 527-544. [CrossRef] [PubMed]

15. Campos-Nañez, E.; Garcia, A.; Li, C. A game-theoretic approach to efficient power management in sensor networks. Oper. Res. 2008, 3, 552-561. [CrossRef]

16. Encarna, E.; Ariel, D. Cooperative management of groundwater resources in the presence of environmental externalities. Environ. Resour. Econ. 2013, 54, 443-469.

17. Lan, S.; Zhong, R. Coordinated development between metropolitan economy and logistics for sustainability. Resour. Conserv. Recycl. 2018, 128, 345-354. [CrossRef]

18. Smith, J. The theory of games and the evolution of animal conflicts. J. Theor. Biol. 1974, 47, 209-221. [CrossRef]

19. Taylor, P.; Jonker, L. Evolutionary Stable Strategies and Game Dynamics. Math. Biosci. 1978, 40, $145-156$. [CrossRef]

20. Antoci, A.; Borghesi, S.; Sodini, M. Water resource use and competition in an evolutionary model. Water Resour. Manag. 2017, 31, 1-21. [CrossRef]

21. Zhang, N.; Chen, Z. Sustainability Characteristics of China's Poyang Lake Eco-Economics Zone in the big data environment. J. Clean. Prod. 2017, 142, 642-653. [CrossRef]

22. Zhou, H.; Luo, Z.; Tangdamrongsub, N.; Zhou, Z.; He, L.; Xu, C.; Li, Q.; Wu, W. Identifying flood events over the Poyang Lake Basin using multiple satellite remote sensing observations, hydrological models and in situ data. Remote Sens. 2018, 10, 713. [CrossRef]

23. Zhang, N.; Kong, F.; Kung, C. On modelling environmental production characteristics: A slacks-based measure for China's Poyang lake ecological economics zone. Comput. Econ. 2015, 3, 389-404. [CrossRef]

24. Fan, H.; Xu, L.; Tao, H. Accessing the difference in the climate elasticity of runoff across the Poyang lake basin, China. Water 2017, 9, 135. [CrossRef]

25. Cai, S.; Shi, H.; Pan, X.; Liu, F.; Cui, Y.; Xie, H. Integrating ecological restoration of agricultural non-point source pollution in Poyang Lake Basin in China. Water 2017, 9, 745. [CrossRef]

26. National Bureau of Statistics. China City Statistical Yearbook; China Statistics Press: Beijing, China, 2016. Available online: http://www.stats.gov.cn/tjsj/tjcbw/201706/t20170613_1502795.html (accessed on 2 June 2019).

27. Wang, Y.; Liu, Y.; Jin, J. Contrast effects of vegetation cover change on evapotranspiration during a revegetation period in the Poyang Lake Basin, China. Forests 2018, 9, 217. [CrossRef]

28. Yang, Z.; Zeng, Y.; Cai, Y.; Tan, T. An integrated game-theory based model for trans-boundary water resources management in North China: A case study in the Granting Reservoir Basin (GRB), Beijing. Int. J. Softw. Eng. Knowl. Eng. 2008, 4, 461-483. [CrossRef]

29. Li, C.; Zhang, L.; Zhao, G.; Mo, L. Research on basin ecological compensation based on evolutionary game theory-taking Taihu basin as a case. China Popul. Resour. Environ. 2014, 1, 171-176. (In Chinese)

30. Zhang, L.; Feng, C. Rationality and Bounded Rationality: On the relationship between classical game theory and evolutionary game theory. J. World Econ. 2001, 8, 74-78. (In Chinese)

31. Yu, X. Transboundary water pollution management Lessons learned from river basin management in China, Europe and the Netherlands. Utrecht Law Rev. 2011, 7, 188-203. Available online: https://www. utrechtlawreview.org/articles/abstract/10.18352/ulr.154/ (accessed on 2 June 2019). [CrossRef]

32. Zhang, N.; Kong, F.; Choi, Y. Measuring sustainability performance for China: A sequential generalized directional distance function approach. Econ. Model. 2014, 41, 392-397. [CrossRef]

33. Li, Z.; Wu, D.C.; Chen, C.; Cao, H.; Gan, J. Transformation game perspective about the cooperation dilemma in the tumen river's navigation and its solutions. Sci. Geogr. Sin. 2013, 4, 393-400. (In Chinese)

34. Huang, F.; Chunyu, X.; Wang, Y.; Wu, Y. Investigation into multi-temporal scale complexity of stream flows and water levels in the Poyang Lake Basin, China. Entropy 2017, 19, 67. [CrossRef]

35. Chen, Y.; Shu, L.; Li, W. Research on coordinated development between metropolitan economy and logistics using big data and Haken model. Int. J. Prod. Res. 2018, 1-14. [CrossRef]

36. Moors, E.; Groot, A.; Biemans, H. Adaptation to changing water resources in the Ganges basin, northern India. Environ. Sci. Policy 2011, 7, 758-769. [CrossRef]

37. Chen, $X$. The coordination among regional profits in the river basin development and management. Econ. Geogr. 2002, 5, 525-529. (In Chinese) 
38. Chen, M.; Lu, Y.; Ling, L.; Luo, Z.; Huang, H. Drivers of changes in ecosystem service values in Ganjiang upstream watershed. Land Use Policy 2015, 47, 247-252. [CrossRef]

39. Zhao, X.; Liu, J.; Liu, Q.; Tillotson, M.; Guan, D.; Hubacek, K. Physical and virtual water transfers for regional water stress alleviation in China. Proc. Natl. Acad. Sci. USA 2015, 4, 1031-1035. [CrossRef]

40. Zhou, C.; Xie, H.; Zhang, X. Does Fiscal Policy Promote Third-Party Environmental Pollution Control in China? An Evolutionary Game Theoretical Approach. Sustainability 2019, 11, 4434. [CrossRef]

41. You, H. Quantifying megacity growth in response to economic transition: A case of Shanghai. Habitat Int. 2016, 53, 115-122. [CrossRef]

42. Garrick, D.; Siebentritt, M.; Aylward, B.; Bauer, C.; Purkey, A. Water markets and freshwater ecosystem services: Policy reform and implementation in the Columbia and Murray-Darling Basins. Ecol. Econ. 2009, 2, 366-379. [CrossRef]

43. Liu, H.; Benoit, G.; Liu, T.; Liu, Y.; Guo, H. An integrated system dynamics model developed for managing lake water quality at the watershed scale. J. Environ. Manag. 2015, 155, 11-23. [CrossRef] [PubMed]

44. Christopoulos, S.; Demir, C.; Kull, M. Cross-sectoral coordination for sustainable solutions in Croatia: The (meta) governance of energy efficiency. Energy Policy 2016, 99, 57-87. [CrossRef]

45. Kim, Y. The international policy coordination to reduce the financial volatility in North East Asia. Glob. Econ. Rev. 1999, 4, 102-116. [CrossRef]

46. He, Y.; Lin, K.; Zhang, F.; Wang, Y.; Chen, X. Coordination degree of the exploitation of water resources and its spatial differences in China. Sci. Total Environ. 2018, 644, 1117-1127. [CrossRef] [PubMed]

47. Abdessalam, A.; Kamwa, E. Tax Competition and Determination of the Quality of Public Goods. Economics 2014, 8, 1-20. [CrossRef]

48. Filippo, C.; Guillaume, G. Policy options for promoting urban-rural cooperation in water management: A review. Int. J. Water Resour. Dev. 2017, 33, 852-867.

49. Cui, D.; Chen, X.; Xue, Y.; Li, R.; Zeng, W. An integrated approach to investigate the relationship of coupling coordination between social economy and water environment on urban scale-A case study of Kunming. J. Environ. Manag. 2019, 234, 189-199. [CrossRef]

50. Munda, G. A conflict analysis approach for illuminating distributional issues in sustainability policy. Eur. J. Oper. Res. 2009, 1, 307-322. [CrossRef]

51. Xie, H.; Jin, S. Evolutionary Game Analysis of Fallow Farmland Behaviors of Different Types of Farmers and Local Governments. Land Use Policy 2019, 88, 1-11. [CrossRef]

52. Xie, H.; Wang, W.; Zhang, X. Evolutionary game and simulation of management strategies of fallow cultivated land: A case study in Hunan province, China. Land Use Policy 2018, 71, 86-97. [CrossRef]

53. Jiang, L.; Tong, Y.; Zhao, Z.; Li, T.; Liao, J. Water Resources, Land Exploration and Population Dynamics in Arid Areas-The Case of the Tarim River Basin in Xinjiang of China. Popul. Environ. 2005, 6, 471-503. 